\title{
REVISITANDO O CONCEITO DE PAISAGEM PARA PENSAR A PRÁTICA DE ENSINO- APRENDIZAGEM DE GEOGRAFIA NA CONTEMPORANEIDADE
}

\author{
Ana Isabel Leite Oliveira \\ Universidade do Estado da Bahia, Campus XI - Serrinha, Brasil \\ ailoliveira@uneb.br \\ Jocimara Souza Britto Lobão \\ Universidade Estadual de Feira de Santana, Bahia, Brasil \\ juci.lobao@gmail.com \\ Ângelo Moura Araújo \\ Universidade do Minho - Portugal \\ arangeo@gmail.com
}

\begin{abstract}
RESUMO
Nas últimas décadas novas orientações teórico-metodológicas têm conduzido um reexame das relações entre sociedade, natureza, tecnologia, ciência e ensino. Para a Geografia, especificamente, Paisagem é um conceito que se originou no campo das artes, ganhou relevância científica com escolas europeias, sofreu descaso decorrente da crítica racionalista da ciência moderna e atualmente ressurge pela necessidade crítica de avaliar as rápidas modificações no nosso ambiente. Diante deste contexto, o nosso objetivo é discutir a ressignificação do conceito Paisagem e o seu potencial teórico-metodológico para o ensino-aprendizagem de Geografia, vinculando-os ao crescente desenvolvimento das Geotecnologias. Para tanto, realizou-se revisão de literatura e se constatou que o papel do ensino de Geografia, assim como do conceito Paisagem, está sendo revisto e, as tecnologias geográficas podem possibilitar a ampliação teórico-metodológica dos estudos espaciais. A nível de reflexão e metodologia de análise, propõem-se pensar as potencialidades do conceito Paisagem, construído historicamente, para o ensinoaprendizagem de Geografia, apresentar possibilidades de análises perceptivas, objetivas, integradas e automatizadas do espaço geográfico em uma perspectiva multiescalar dos fenômenos, com vistas à formação social e integral do indivíduo.
\end{abstract}

Palavras-chave: Paisagem. Geotecnologias. Ensino-Aprendizagem de Geografia.

\section{REVISITANDO EL CONCEPTO DE PAISAJE PARA PENSAR LA PRÁCTICA DE LA ENSEÑANZA Y APRENDIZAJE DE LA GEOGRAFÍA EN LA CONTEMPORANEIDAD}

\section{RESUMEN}

En las últimas décadas nuevas propuestas teórico-metodológicas ha conducido a una revisión de las relaciones entre sociedad, naturaleza, tecnología, ciencia y enseñanza. Para la geografía, específicamente, el paisaje es un concepto que se originó en el campo de las artes, adquirió relevancia científica con las escuelas europeas, sufrió descuido derivado de la crítica racionalista de la ciencia moderna y actualmente resurge por la necesidad crítica de evaluar la cambios rápidos en nuestro entorno. Por lo anterior, nuestro propósito es discutir la resignificación de la noción de paisaje y su potencial teórico-metodológico para la enseñanza y aprendizaje de la geografía, vinculándolos al creciente desarrollo de las Geotecnologias. A tal fin, se revisó la literatura y se constató que el papel de la enseñanza de geografía, así como del concepto Paisaje, está siendo revisado y las tecnologías geográficas pueden permitir la expansión teórica y metodológica de los estudios espaciales. Para tal reflexión, proponemos pensar en el potencial del concepto paisaje, construido históricamente, para la enseñanza y aprendizaje de geografía, presentar posibilidades de análisis perceptivas, objetivas, integradas y automatizadas del espacio geográfico en una perspectiva multiescalar de los fenómenos, con vistas a la formación social y integral de la persona.

Palabras clave: Paisaje. Geotecnologias. Enseñanza y Aprendizaje de la Geografía. 


\section{INTRODUÇÃO}

Nas últimas décadas novas orientações teórico-metodológicas, provenientes de mudanças na visão de mundo, têm conduzido um reexame das relações entre sociedade, natureza, tecnologia, ciência e ensino. Para a Geografia, especificamente, os pensamentos sistêmico, holístico, complexo, interdisciplinar, multiescalar alinhados aos avanços das tecnologias geográficas, proporcionam novas reflexões, o repensar conceitos e métodos, tanto para a academia como para o ensino básico.

Diante deste contexto, o nosso propósito é discutir a ressignificação do conceito Paisagem e o seu potencial teórico-metodológico para o ensino de Geografia, vinculando-os ao crescente desenvolvimento das geotecnologias, por meio de revisão de literatura. Paisagem é um conceito que se originou no campo das artes, ganhou relevância científica com escolas europeias, sofreu descaso decorrente da crítica racionalista da ciência moderna e atualmente ressurge, de acordo com Turner et al. (2001), pela necessidade crítica de avaliar o rápido impacto, as modificações de larga escala no nosso ambiente.

Polissêmico e polêmico, para os moldes das ciências modernas, Paisagem é objeto de estudo desde os primórdios da Geografia. Transita entre a corrente Tradicional, Teorética Quantitativa até a Humanista e Fenomenológica, adequa-se desde o mapeamento e a métrica até as interpretações subjetivas. E exatamente por essa característica multifacetada se renova e se ressignifica, ganha relevância nas investigações para o entendimento da sociedade contemporânea, a qual requer novas formas de leitura da realidade. Ao abandonar a dicotomia para integrar a dualidade unificadora, por meio das geotecnologias, a Paisagem abarca porções do espaço que a visão do olho humano já não mais alcança e possibilita interconexões, análises e sínteses cada vez mais complexas.

Partimos assim de uma sucinta evolução do conceito Paisagem, necessária para compreendermos as variadas abordagens que pode nos proporcionar. Demarcamos a preferência por pensar pluralmente, não de forma dicotômica. Para o nosso ponto de chegada - ensino de Geografia, essa compreensão abre amplos espaços para intervenções pedagógicas sob variadas orientações teóricas e conduções procedimentais, faculta-nos a destituição de relações unívocas para a formação de indivíduos socialmente integrados e capazes de melhor compreender e intervir nos processos atuais.

\section{CONSIDERAÇÕES SOBRE O CONCEITO PAISAGEM}

O conceito Paisagem, que já foi considerado objeto da Geografia no início do século XIX e depois secundarizado em relação a outros conceitos geográficos, tem passado nos dias atuais por ressignificações (SANTOS, 1997; HOLZER, 1999; LUCHIARI, 2001; BESSÉ, 2006). Revistas filosóficoepistemológicas, pelas quais as bases modernas da produção de conhecimento e a evolução tecnológicainformacional têm atravessado, influenciam e são influenciadas pelos novos olhares sobre a dinâmica da natureza e da sociedade contemporânea, conduzindo sua retomada a partir de concepções integradoras.

Leff (2013) argumenta que as diversas disciplinas foram chamadas a incorporar valores e princípios ecológicos em função da globalização da degradação socioambiental. Necessitando explicar processos de ordem física, biológica, tecnológica e social pela apreensão de sua causalidade múltipla e potencial sinergético, as referências dos paradigmas unidisciplinares do pensamento moderno tornaram-se insuficientes. A compressão deste contexto se faz necessária para que possamos entender a revisão pela qual passa o conceito Paisagem, parte importante do nosso foco de discussão, a qual se coloca no plano filosófico-epistemológico da ciência como um todo.

Relembremos que a origem do conceito Paisagem é renascentista, inicialmente presente na expressão das artes (pintura e poesia), baseada na linguagem cotidiana, popular, retratando cenários do ponto de vista central e externo de um observador (SANTOS, 1997; CLAVAL, 2004; LANG e BLASCHKE, 2009). Segundo Holzer (1999), isso trouxe o primeiro grande desafio para a Geografia em relação a este conceito, pois a pouca contribuição das reflexões filosóficas que não estéticas, foi determinante para que outras disciplinas e o senso comum a concebessem enquanto uma cena, um espaço apreendido segundo um campo de visão.

Captar e delimitar a Paisagem segundo este viés, deparou-se com forte influência da percepção do observador, conduzindo a múltiplas leituras e representações. Isto trouxe limitações do ponto de vista científico, que no início do século XIX, baseava-se em uma visão objetiva, linear, mecânica e fragmentada, conferida pelos fundamentos do racionalismo, mecanicismo, empirismo e busca de explicações matematizadas.

$\begin{array}{llllll}\text { Caminhos de Geografia } & \text { Uberlândia - MG } & \text { v. 19, n. } 68 & \text { Dez/2018 } & \text { p. 286-295 } & \text { Página } 287\end{array}$


Avançando geograficamente neste conceito, segundo Rodriguez et al. (2013) duas vertentes ganharam destaque: as escolas alemã e russo-soviética, originadas dos estudos de Humbold e Dokuchaev, que concebiam a paisagem como um complexo natural integral e as escolas francesas, anglo-saxônica e europeia-ocidental, que concebiam paisagem como espaço social ou entidade perceptiva.

Dessas escolas derivam diversas terminologias as quais não poderíamos deixar de fazer referência pela ampla discussão que suscitam: Landschaft para os alemães, Paysage para os franceses e Landscape para os norte-americanos. De maior complexidade, o termo alemão remonta à época medieval, que realiza associação entre homem/cultura e natureza/morfologia. Paysage, também incorporado pelo inglês, tem duas possiblidades de leitura, o de termo renascentista vinculado às artes plásticas, assim como entendido pela derivação do radical Pays que significava na Idade Média, simultaneamente, "habitante" e "território". E os franceses aproximaram-se da compreensão alemã ao prescindir da acepção renascentista (HOLZER, 1999).

Assim, fortemente influenciada pelas tradições de Humboldt e outros geógrafos naturalistas, a Geografia acadêmica surgiu na Europa enquanto disciplina, concomitantemente, às reflexões geográficas para o desenvolvimento do conceito Paisagem. Afirmando-se como objeto de estudo da ciência Geográfica neste período, o conceito distanciou-se do entendimento renascentista. A Paisagem foi associada "à porções do espaço relativamente amplas, que se destacavam visualmente por possuírem características físicas e culturais suficientemente homogêneas para assumirem uma individualidade" (HOLZER, 1999, p. 151).

Na década de 1950, o paradigma quantitativo influenciou fortemente a Geografia, para a qual as "fragilidades" presentes no conceito Paisagem suscitaram fortes críticas. Se por um lado Paisagem podia ser vista como uma possibilidade de leitura integrada para os fenômenos geográficos, estudada por um viés naturalista focado no fenômeno e não em sua representação, a falta de um aparato metodológico para sua delimitação e análise causava desconforto.

Desta forma, de objeto da Geografia a Paisagem passou a ser marginalizada. Essa nova Geografia tinha por finalidade gerar leis de localização, observar áreas que vão além do campo de visão, comparar mapas temáticos em escalas variáveis e quantificáveis, interessava-se pelo estudo das redes urbanas, para as quais a existência de dados codificados permitiam executar uma modelagem matemática (GOSME, 2005).

Mas este direcionamento não foi homogêneo. Na França, especialistas da Geografia Física de sensibilidade biogeográfica fizeram da questão da paisagem uma especialidade, desenvolvendo a cartografia da paisagem. Na Geografia Humana, ocorreu a reafirmação da dimensão da identidade e do sensível. Aspectos culturais foram valorizados, foi reconhecido que a consciência humana capta originalidades individuais da paisagem, enfatizando-se assim o espaço vivido (GOSME, 2005).

A vertente física da Geografia foi muito influenciada pela Teoria Geral dos Sistemas (TGS), firmada com Bertrand (2004) preocupação epistemológica e metodológica, que assim a definiu:

É, em uma determinada porção do espaço, o resultado da combinação dinâmica, portanto instável, de elementos físicos, biológicos e antrópicos que, reagindo dialeticamente uns sobre os outros, fazem da paisagem um conjunto único e indissociável, em perpétua evolução. (BERTRAND, 2004, p. 141).

Esta concepção confere dinamicidade a paisagem, pois esta é fruto das interações entre sociedade e natureza, que se influenciam mutuamente, criando complexos sistêmicos individualizados pela condição destas interações. Não se trata mais de observar elementos presentes em dada porção do espaço geográfico, mas de considerar transformações neste espaço ao longo do tempo, cujo resultado é uma estrutura, uma organização resultante da ação antrópica com feições próprias e em constante movimento.

Demonstrando outras influências, nos estudos da Geografia Humana, Santos (1997) cita o norteamericano Carl Sauer e o alemão Karl Marx, destacando que o primeiro é o "pai" da geografia cultural e que propôs uma categorização do conceito paisagem: (a) paisagem natural, intocada pelo homem, cujo conceito é criticado por Santos (1997), ao compreender que na atualidade, mesmo quando não diretamente transformado, interesses econômicos e políticos agem sobre o espaço; (b) paisagem artificial, resultante da relação cultural com a paisagem natural.

$\begin{array}{llllll}\text { Caminhos de Geografia } & \text { Uberlândia - MG } & \text { v. 19, n. 68 } & \text { Dez/2018 } & \text { p. 286-295 Página } 288\end{array}$


Em um direcionamento fenomenológico, próprio da Geografia Cultural, a paisagem é considerada sob o ponto de vista do espaço vivido, da experiência do sujeito, conhecida por suas "forças nãoobserváveis, que são subjetivas" (HOLZER, 1999). Já sob a influência do marxismo, a relação não mais recai sob o aspecto cultural, mas passa a ser vista como uma relação de socialização.

Fundamentado não apenas no materialismo histórico, como também em princípios do pensamento sistêmico e complexo, Santos (1997) define paisagem como "um conjunto de formas heterogêneas, de idades diferentes, espaços de tempos históricos representativos das diversas maneiras de produzir as coisas, de construir o espaço" (p. 68). A heterogeneidade deriva das "múltiplas funções" da vida em sociedade, as quais se relacionam ao modo de produção e originam múltiplas formas e atores, configura a paisagem segundo os níveis de produção, circulação, distribuição e consumo, constitui sistemas de relações subordinados a um sistema global.

E sob este viés, o conceito de Paisagem ganha importância frente aos estudos ambientais e ao desenvolvimento de metodologias que conferem maior operacionalidade a este conceito, inclusive diante das inovações tecnológico-informacionais, mais especificamente das tecnologias Geográficas. Pois, a sua ressignificação perpassa pela mudança de visão que as questões ambientais têm empreendido, assim como as potencialidades tecnológicas para intervenção física e de gestão dos espaços sociais.

Lang e Blaschke (2009) declaram que desde o final do século XIX a descrição de paisagens é realizada com base na observação do padrão espacial, e que esta pode ser concebida enquanto estrutura espacial heterogênea, mas apresenta caráter integrador guardando diferentes homogeneidades tópicas. Assim, a unidade da paisagem irá depender da respectiva escala de observação, onde poderão ser visualizados limites de superfícies homogêneas com certa nitidez.

A observação desses padrões tem ocorrido, recorrentemente, por meio do uso de fotografias aéreas, imagens obtidas por Sensoriamento Remoto e Sistemas de Informações Geográficas (SIG) e trabalhos de campo, ressaltada a origem do SIG, a qual se encontra diretamente relacionada ao planejamento de paisagem e meio ambiente. Assim, metodologicamente detectável, considera-se que a paisagem apresenta características estruturais, as quais podem ser observadas, descritas e quantificadas, além de explicadas e compreendidas pelos processos que nela ocorrem. Estrutura da paisagem é um conceito jovem, também entendido como concepção norte-americana de ecologia da paisagem que se desenvolveu no seio da Geoinformática, estabelecido nas décadas de 1980 e 1990 (LANG e BLASCHKE, 2009, p. 93).

A Ecologia da Paisagem, surge da tentativa de unificar conceitos da Ecologia e da Geografia, com intenso desenvolvimento teórico-metodológico nos dias atuais. Termo provavelmente cunhado por Troll, em 1935, pode ser entendido como o estudo das interações entre os organismos e o seu ambiente. Nesta concepção, uma paisagem estende-se em qualquer direção até que determinada unidade ecossistêmica se modifique (FORMAN, 1995). Assim, resumindo metodologicamente, o conceito de estrutura da paisagem apoia-se em três aspectos básicos: estrutura, função e desenvolvimento e mudança (Figura 1).

Figura 1: Aspectos básicos da estrutura da paisagem.

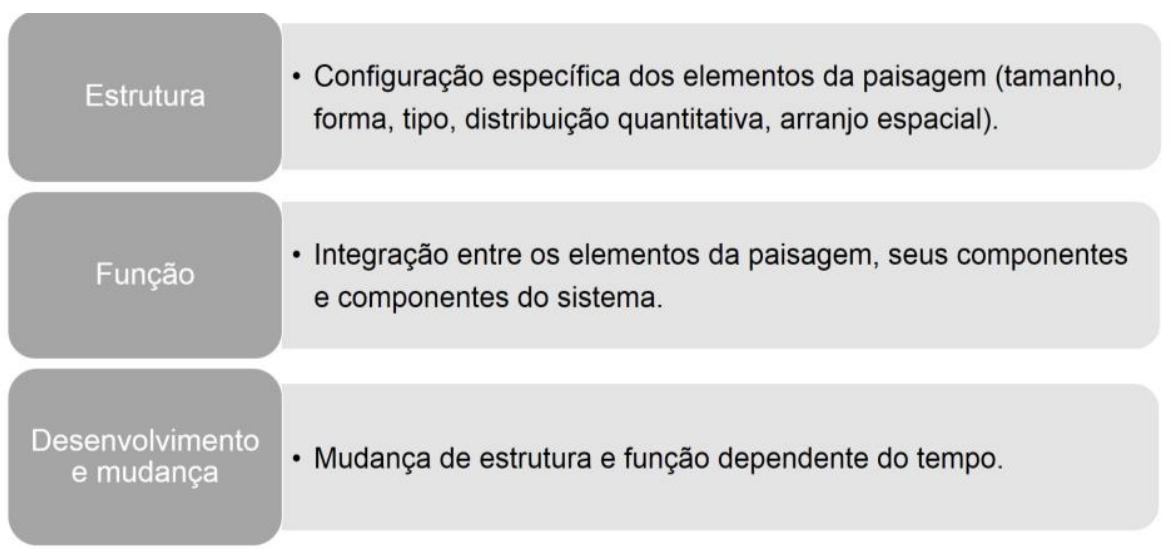

Fonte: Baseado em Lang e Blaschke (2009). 
Neste contexto a paisagem é entendida como sistema integrador, composta por elementos sociais e naturais, com pelo menos um fator de caráter heterogêneo contido em uma área. É considerada a existência de relações recíprocas no sistema "Homem-Meio Ambiente" em todas as esferas e dimensões, cuja forma de expressão sobre a paisagem é o uso do solo. Tais concepções, afirmam Lang e Blaschke (2009), aproximam a ecologia da paisagem do caráter interdisciplinar, sendo indispensáveis para lidar com problemas complexos sob os pressupostos do desenvolvimento sustentável.

Estão postos assim, novos caminhos para o estudo analítico da paisagem, definido por Lang e Blaschke (2009), como o "estudo analítico da configuração da paisagem e seu desenvolvimento e as implicações específicas resultantes dessa configuração para a integridade, utilidade e valor da paisagem" (p. 111). A requerida delimitação e explicação de um objeto, pelo reconhecimento de suas estruturas conforme escala de análise. Uma metodologia que confere cientificidade, dentro do requerido pressuposto das ciências modernas para este conceito.

Já Rodriguez et al. (2013) afirma que predomina na ciência geográfica e biológica a concepção antroponatural, ou seja, formada por "elementos naturais e antropotecnogênicos condicionados socialmente" (p. 15), os quais encontram-se hierarquicamente organizadas. Mas, destaca que pode ser considerada como um "sistema que contêm e reproduz recursos; como meio de vida e da atividade humana; como laboratório natural e fonte de percepção estética". Ou seja, diante do breve histórico traçado, verificamos que permanece a polissemia que atribui imprecisão a este conceito, bem como a histórica dicotomia entre o físico e o humano.

Fato é que, na atualidade, Lang e Blaschke (2009) reafirmam esta nossa constatação, pois consideram que as questões que envolvem este conceito ainda não foram resolvidas, já que tenta-se "aproximações quantitativas e qualitativas a padrões de pensamento sistêmico-holístico" (p. 93). Trata-se portanto, de superar a fragmentação na produção do conhecimento ora inculcada pela ciência moderna.

No entanto, se a fragmentação levou ao distanciamento dos métodos nas áreas física e humana, se o positivismo questiona sobre o que é válido ou não enquanto conhecimento produzido, a necessária reintegração dessas partes para compreender os resultados desta fragmentação nas organizações sociais e nas suas relações com a natureza, nos mostra um vasto potencial para o conceito de paisagem nesta perspectiva de integração. Vejamos a definição de paisagem dada por Berque:

\begin{abstract}
(...) a paisagem não reside somente no objeto, nem somente no sujeito, mas na interação complexa entre os dois termos. Esta relação que coloca em jogo diversas escalas de tempo e espaço, implica tanto a instituição mental da realidade quanto a constituição material das coisas (BERQUE, 1994, p. 5 apud HOLZER, 1999, p. 163).
\end{abstract}

Tendo em vista a prática de ensino, constatamos que esta concepção está presente nos Parâmetros Curriculares Nacionais de Geografia. A integração entre a realidade empírica e sensorial pode ser compreendida em sua definição:

\footnotetext{
Uma paisagem, seja de uma rua, de um bairro, ou de uma cidade, além de representar uma dimensão concreta e material do mundo, está impregnada de significados que nascem da percepção que se tem dela. No seu cotidiano os alunos convivem de forma imediata com essas representações e significados que são construídos no imaginário social. (BRASIL, 1998, p. 23).
}

Consideremos assim, objetividade e subjetividade, abstração e materialidade, em uma relação dialética. Ao mesmo tempo em que se distanciam em termos de métodos de investigação científica, se aproximam para a interpretação, compreensão e explicação integral dos fenômenos na sociedade complexa atual. Vive-se um momento de ruptura epistemológica, consequentemente de dificuldades de discernir a validade do "velho" e do "novo", de negação para afirmação de novos pressupostos, de repensar conduções metodológicas. Mas também de agregação de contrários, compreendendo que por sua complexidade a realidade abarca pluralidade de ideias. 


\section{POTENCIAIS CONTRIBUIÇÕES DA PAISAGEM E GEOTECNOLOGIAS PARA A PRÁTICA DE ENSINO EM GEOGRAFIA}

No Brasil, a Geografia sofre grande influência da escola francesa. Insere-se primeiro como disciplina escolar no colégio Pedro II, no Rio de Janeiro em 1837, para depois se estabelecer como curso superior na Fundação da Faculdade de Filosofia, Ciências e Letras da Universidade de São Paulo e do Departamento de Geografia, em 1934. No século XIX, a Geografia vidaliana praticada era a dos lugares e não dos homens, ou seja, destituída de representações simbólicas (BRASIL, 1998).

Essa Geografia, marcada pelo positivismo, constituiu no Brasil a denominada Geografia Tradicional, a qual orientou o estudo descritivo da paisagem com procedimentos didáticos pautados na memorização. Os alunos, assim como os pesquisadores, buscavam explicar a realidade com base no que observavam concretamente, sem interpretar para não incorrer no considerado erro da subjetividade, para não macular a neutralidade da ciência geográfica moderna.

Na década de 1970, fortemente influenciada pela teoria marxista, a denominada Geografia Crítica, tinha o propósito de questionar o pensamento geográfico, tanto acadêmico como escolar, dito neutro e ingênuo, reconhecendo a ideologia e o utilitarismo que o permeava. Conforme Cavalcanti (2010) "a proposta era de uma nova estrutura, cujo eixo era o espaço e as contradições sociais, orientando-se pela explicação das causas e decorrências das localizações de certas estruturas espaciais" (p. 5). Contradições sociais essas vistas como originadas em uma sociedade de classes, marcada pela divisão do trabalho, pelos diferentes meios de produção, que imprimiam paisagens pelas diferentes e desiguais formas de apropriação dos espaços.

Assim, o denominado Movimento de Renovação da Geografia, ocorrido no Brasil no final da década de 1970, marcou o início de transformações impulsionadas pela análise dos fundamentos teóricometodológicos da ciência geográfica, bem como pelas proposições de como transpor seus conhecimentos para o ensino, deslocando-se da abordagem tradicional para a crítica (CORRÊA, 2001; CAVALCANTI, 2010). Mudou-se o foco da explicação dos fatos e fenômenos geográficos para a formação de indivíduos capazes de compreender e transformar a realidade. Então, questionou-se o papel da escola e da Geografia Escolar quanto a sua função social, o que perpassava pela revisão de conteúdos e métodos.

Também, a dimensão cultural e tecnológica impregnada nas experiências de vida e as representações simbólicas e do real, presentes no cotidiano da sociedade, começaram a ganhar visibilidade. Novas propostas metodológicas surgiram em articulação com a Pedagogia e a Didática, perante o reconhecimento de que:

\footnotetext{
(...) mudanças relacionadas ao cotidiano espacial de uma sociedade globalizada, urbana, informacional, tecnológica requerem uma compreensão do espaço que inclua a subjetividade, o cotidiano, a multiescalaridade, a comunicação, as diferentes linguagens do mundo atual. (CAVALCANTI, 2010, p. 5).
}

Diante dessas orientações, ao revisar o conceito de Paisagem percebemos o seu grande potencial para introdução desses aspectos no processo de ensino-aprendizagem. A exploração da linguagem imagética seja pela pintura, gravura, fotografia, vídeo, cenas observadas do cotidiano, imagens obtidas por sensoriamento remoto, modelos matemáticos, etc., é uma condução própria da leitura da paisagem. Esta pode expandir-se para a elaboração das representações ou modelos, para sua compreensão e explicação em diversas escalas com a conciliação de recursos tecnológicos específicos, do local ao global (Figura 2), com base tanto na percepção como na interpretação.

Quanto à distinção entre percepção e interpretação, Santos (1997) esclarece a necessidade de diferenciar percepção e conhecimento, ao afirmar que "Nossa tarefa é ultrapassar a paisagem como aspecto, para chegar ao seu significado" (p. 62). Para tanto, a interpretação coloca-se como a chave para o conhecimento, para superação da aparência. A paisagem guarda em si elementos sensitivos/culturais, visíveis e forças organizadoras não visíveis, as quais precisam ser interpretadas.

Voltando-nos para os avanços tecnológicos, novos desafios para o ensino da Geografia são colocados, assim como são ampliadas as suas possibilidades. Buzai (2004) chama a atenção para o fato de a inteligência espacial começar a ocupar lugar de destaque junto às habilidades intelectuais que são tradicionalmente valorizadas. Considera que a Geografia impacta de forma notável não só nas diversas disciplinas, mas principalmente no pensamento humano, que ganha relevância na revolução intelectual que vislumbra.

\begin{tabular}{llllll}
\hline Caminhos de Geografia & Uberlândia - MG & v. 19, n. 68 & Dez/2018 & p. 286-295 & Página 291
\end{tabular}


Figura 2: Hierarquia espacial da paisagem.

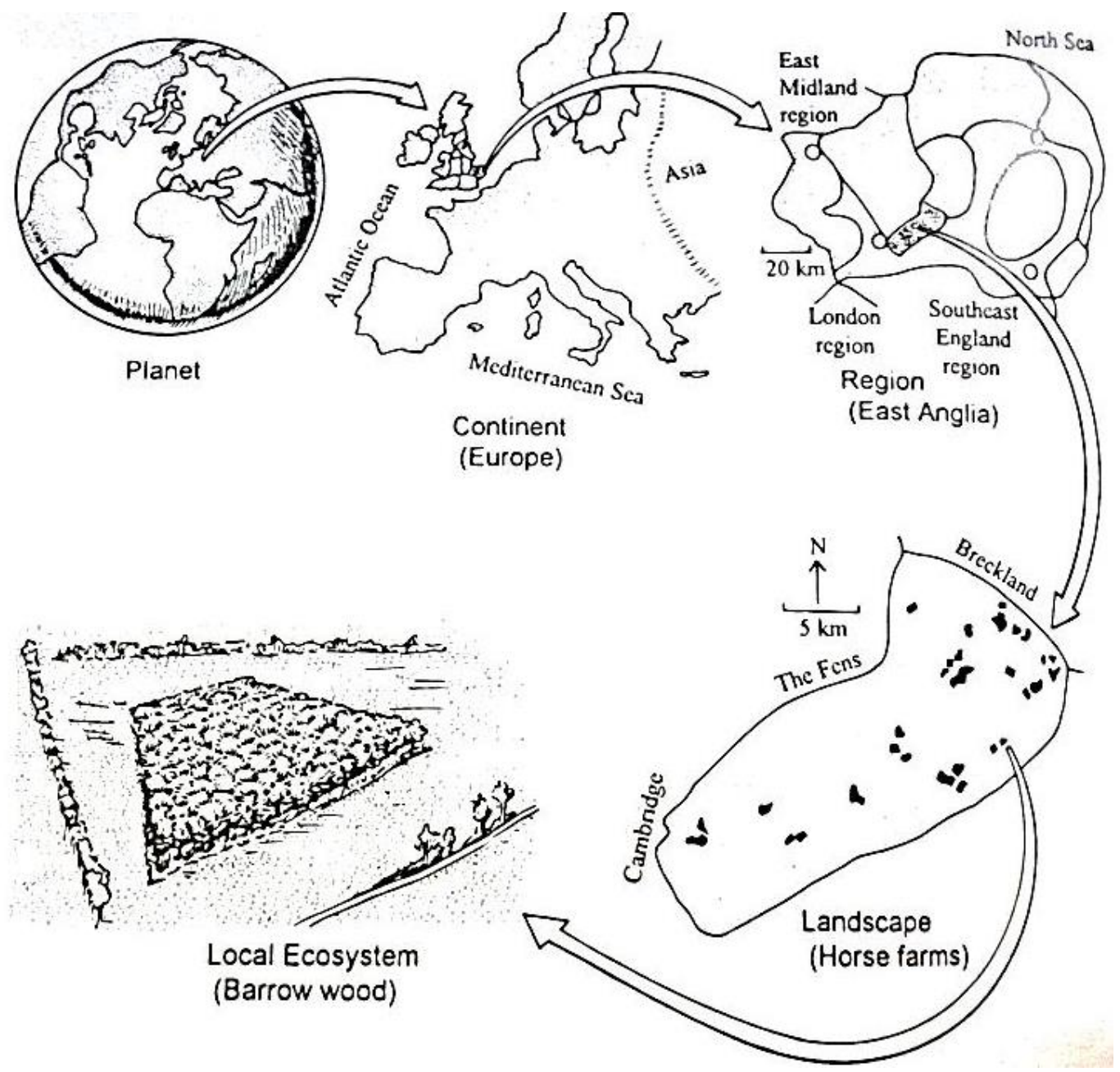

Fonte: Forman, 1995.

Este mesmo autor sugere que a década de 1990 deveria representar um novo ponto de ruptura, por verificar uma evolução para um campo de conhecimento tripartido formado pela Ecologia da Paisagem, a Geografia Pós-Moderna e a Geografia Automatizada, ou seja, um campo denominado Geografia Global. Este, surgido de uma nova visão de mundo propiciada pela incorporação dos conceitos e metodologias geográficos nos sistemas computacionais, apresentando como resultado a inserção da Geografia em outros campos ou disciplinas, torna-se sua maior visibilidade.

A Geografia pode ser considerada Pós-Moderna pela leitura da incerteza, não aceitação da visão de progresso, surgimento de nova agenda social e política em função das preocupações ambientais e dos movimentos sociais, pela constituição de uma nova ordem (SALVI, 2000), ou seja, um contraponto ao racionalismo moderno.

Quanto a Geografia Automatizada, esta pode ser vista como uma disciplina particular que utiliza sistemas cibernéticos, humanos e eletrônicos para a análise de sistemas físicos e sociais, conforme primeiro debate formal realizado por Dobson, em 1983. É integrada pela Cartografia Computacional, Computação Gráfica, Processamento Digital de Imagens de Sensores Remotos, Modelos Digitais de Elevação e Sistemas de Informações Geográficas. Sobre ela deposita-se certa expectativa pela preponderância da visão da realidade por meio de modelos, desprendem se esforços para solucionar a velha dicotomia geográfica (BUZAI, 2004). 
Observa-se que no âmbito da pesquisa científica, dos negócios, da gestão territorial, as geotecnologias já foram bem absorvidas e possibilitam estudos e intervenções cada vez mais acuradas no espaço geográfico. Cabe ampliar as discussões sobre a apropriação dessas tecnologias no ensino da Geografia, explorando o seu potencial pedagógico e social. Docentes e discentes precisam refletir criticamente sobre essa explosão tecnológica, seus usos e interesses, repensar sobre o próprio papel da Geografia diante desta automatização, e encontrarem-se capacitados para se apropriarem destas novas ferramentas como sujeitos sociais.

As propostas pedagógicas recentes mostram a tendência de enfatizar o aluno enquanto construtor no processo e não reprodutor de conhecimento, de levar em consideração seus conhecimentos prévios, de buscar a geografia do cotidiano, de selecionar conceitos geográficos básicos para estruturar os conteúdos de ensino, de definir conteúdos procedimentais e valorativos para a orientação de ações, atitudes e comportamentos socioespaciais (CAVALCANTI, 2002).

De tal modo, a reflexão crítica, a percepção cultural, a possibilidade do uso pedagógico das geotecnologias, o papel construtor do aluno no processo de ensino e aprendizagem, a atribuição de significado ao que se ensina e se estuda, potencialmente rompem os métodos do positivismo e do rígido marxismo. Interliga a Geografia a outros campos do saber, promove o olhar da interconexão entre natureza e sociedade, nas mais variadas escalas e dos mais variados pontos de vista.

Os pilares para considerações sobre novas propostas metodológicas perpassam por bases teórico-filosóficas que devem abarcar a forma como o professor compreende a produção do conhecimento, o papel dos sujeitos envolvidos no processo, a importância social dos conteúdos selecionados, o papel da escola e da Geografia na vida dos sujeitos na sociedade técnicacientifica-informacional.

Neste intento, almejamos uma metodologia que reúna os procedimentos gerais do ensino e os conceitos e procedimentos específicos da Geografia. O esquema a seguir (Figura 3) visa conduzir reflexões sobre o revisitar as práticas de ensino em Geografia diante da ressignificação do conceito Paisagem, considerando-o como um norteador teórico-metodológico, bem como da apropriação das geotecnologias pelos profissionais da educação. As tecnologias geográficas podem ser vistas como potencializadoras da aprendizagem teórica, prática e significativa, da criatividade e do reconhecimento dos alunos enquanto sujeitos no processo de aprendizagem e em sua relação com mundo.

Cavalcanti (2010) declara que, mesmo com as práticas tradicionais sendo dominantes, houve avanços no entendimento e no encaminhamento dos processos de ensino na Geografia escolar, pois

(...) muitos professores têm procurado ser inovadores, variando métodos, procedimentos e linguagens, desenvolvendo aulas em espaços não convencionais, praticando a interdisciplinaridade, utilizando diferentes recursos de forma mais contextualizada com o mundo do aluno, superando o formalismo e a abordagem excessivamente teórica. (CAVALCANTI, 2010, p. 13).

Essa inovação pode ser potencializada pela seleção da Paisagem como um conceito base para a construção do conhecimento no ambiente escolar. A atual dinâmica socioambiental e os avanços no meio técnico-informacional questionam o racionalismo das ciências modernas, sugerem a superação da fragmentação das especialidades disciplinares e do modo de ver a realidade. A Paisagem oferece possibilidades de leituras subjetivas e objetivas por meio de análises que podem ser baseadas tanto na percepção pela exploração da geografia do cotidiano, como na compreensão da dinâmica integrada dos elementos que a compõe, seja pela observação direta e interpretação dos fenômenos ou pelo seu alinhamento às tecnologias geográficas, nas mais variadas escalas. 
Figura 3: Paisagem enquanto conceito teórico-metodológico norteador para o ensino de Geografia.

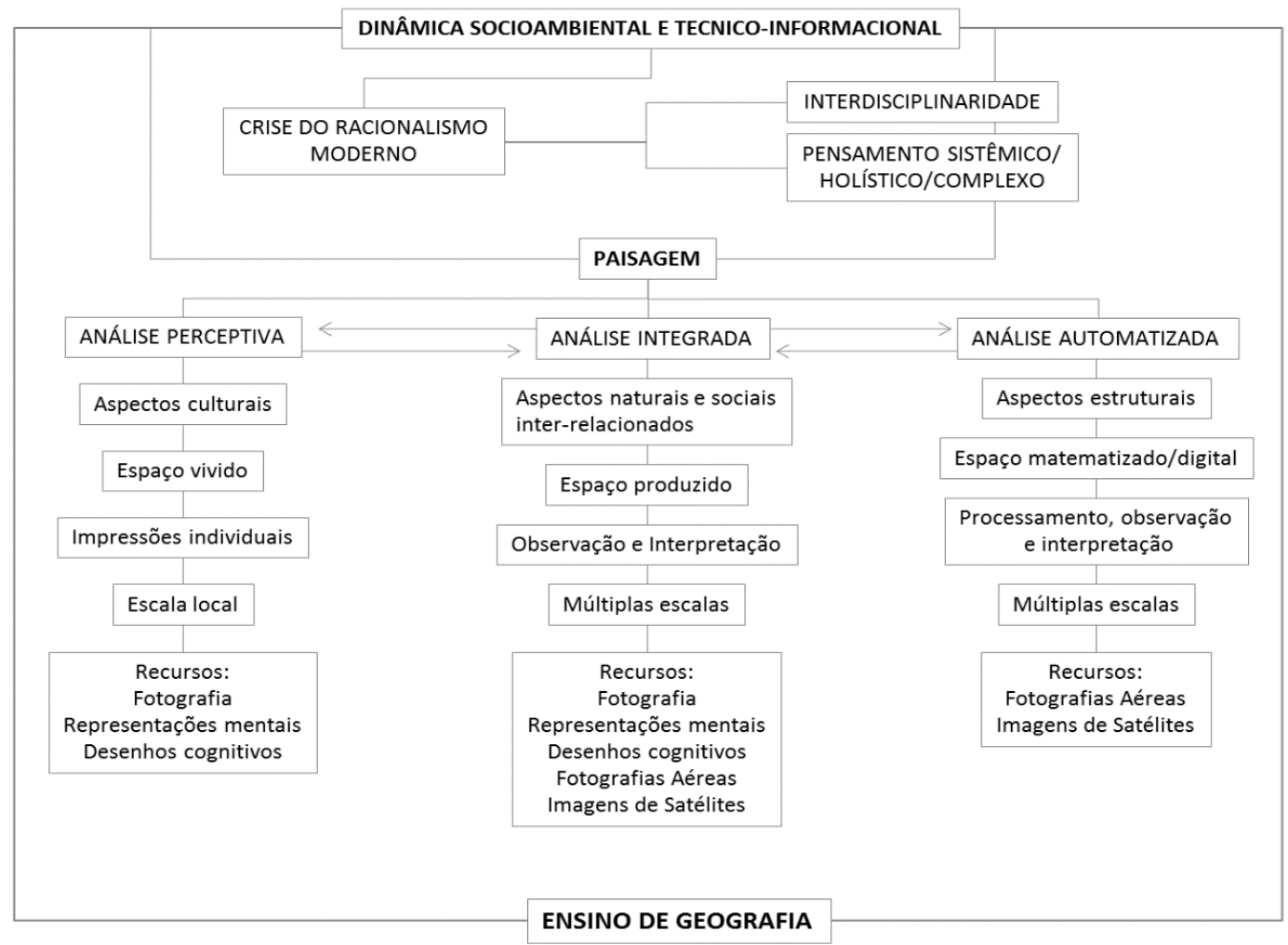

Fonte: Elaborado pelos autores.

\section{CONSIDERAÇÕES FINAIS}

Baseando-nos nas reorientações para a produção de conhecimento e condução do ensino nessas últimas décadas, nos parece claro que está havendo um retorno à humanização e a visão integrada de mundo. Queremos dizer que, do distanciamento estabelecido entre o objeto de estudo e o sujeito cognoscente, o objeto deixa de assumir foco privilegiado e único. O sujeito como um ser social e sensorial passa a se tornar visível aos olhos da ciência, mesmo que ainda de forma incipiente, do mesmo modo que a fragmentação começa a ceder lugar para a totalidade.

Para tanto, sobressai a anunciada necessidade de superar o denominado ensino tradicional da Geografia, assim como apenas focar o seu forte viés econômico e político de explicação e compressão. No entanto, sem abandoná-los, somos chamados a nos debruçar sobre as possibilidades de novas leituras do objeto a partir do sujeito e para o sujeito. $O$ que metodologicamente se traduzirá em práticas de ensino que consideram a descrição, a memorização, a observação, mas também, a percepção individual e coletiva da realidade, a interpretação, a contextualização, as múltiplas linguagens e ferramentas da área específica, a preocupação na transposição deste conhecimento para a vida cotidiana, tornando-o instrumento de mudança.

Uma proposta que nos parece ser bastante viável para atender a essas necessidades, é a adoção da Paisagem enquanto conceito e procedimento orientador do processo de ensino-aprendizagem. $\mathrm{O}$ atual modelo de ciência e ensino já apresenta traços de ruptura. Com a visão de totalidade potencial no conceito Paisagem e apropriação dos avanços nas técnicas para o estudo do espaço geográfico, o ensino de Geografia pode atender às expectativas normativas da educação brasileira e de formação voltada para um sujeito que irá se construir e construir conhecimento enquanto indivíduo e enquanto sociedade.

\section{REFERÊNCIAS}

BERTRAND, G. Paisagem e Geografia Física Global: esboço metodológico. Revista RA’E GA, Curitiba, Editora UFPR, n. 8, p. 141-152, 2004.

\begin{tabular}{llllll}
\hline Caminhos de Geografia & Uberlândia - MG & v. 19, n. 68 & Dez/2018 & p. 286-295 & Página 294
\end{tabular}


BESSÉ, Jean-marc. Ver a Terra, seis ensaios sobre a paisagem e a geografia. São Paulo:

Perspectiva. 2006. 108 p. Disponível em: <https://www.skoob.com.br/livro/pdf/ver-aterra/livro:136819/edicao:152111>. Acesso em: 27 jul. 2018.

BRASIL, Ministério da Educação. Parâmetros Curriculares Nacionais: geografia. Brasília, MEC/SEF, 1998.

BUZAI, G. D. Geografía y tecnologías digitales del siglo XXI: una aproximación a las nuevas visiones del mundo y sus impactos científico-tecnológicos. Revista Eletrónica de Geografía y Ciencias Sociales. Univerdidad de Barcelona, v. VIII, n. 170 (58), p. 1-12, ago 2004.

CAVALCANTI, L. de S. A geografia e a realidade escolar contemporânea: avanços, caminhos, alternativas. In: Seminário Nacional: currículo em movimento - Perspectivas Atuais, 1, 2010. Belo Horizonte Anais. Belo Horizonte, nov 2010.

CAVALCANTI, L. de S. Geografia e práticas de ensino. Goiania: Alternativa, 2002.

CLAVAL, Paul. A paisagem dos geógrafos. In: CORRÊA, Roberto Lobato e ROSENDAHL, Zeny (orgs.). Paisagens, texto e identidades. Rio de Janeiro: EDUERJ. p. 13-74. 2004. Disponível em: <https://pt.scribd.com/document/119538585/paisagem-texto-identidade>. Acesso em: 27 ju.l 2018.

CORRÊA, Roberto Lobato. Espaço, um conceito-chave da geografia. In: CASTRO, I.E. de; GOMES, P. C. da C.; CORRÊA, R.L. (Org.) Geografia: conceitos e temas. Rio de Janeiro: Bertrand Brasil, 2001.

FORMAN, R. T. T. Land Mosaics: the ecology of landscapes and regions. Cambridge University Pres: New York, 1995. https://doi.org/10.1017/9781107050327

GOSME, Cyril. Historique du paysage. Hypergeo. 2005. Disponível em: <http://www.hypergeo.eu/spip.php?article289>. Acesso em: 10 out. 2017.

HOLZER, W. Paisagem, imaginário, identidade: alternativas para o estudo geográfico. In:

ROSENDAHL, Z; CORRÊA, R. L. Manifestações da cultura no espaço. Rio de Janeiro: EdUERJ, 1999.

LANG, S; BLASCHKE, T. Análise da Paisagem com SIG. Tradução Hermann Kux. São Paulo: Oficina de Texto, 2009.

LEFF, Enrique. Saber Ambiental: sustentabilidade, racionalidade, complexidade e poder. Tradução Lúcia Mathilde Endlich Orth. 10. ed. Petrópolis: Rio de Janeiro: Vozes, 2013.

LUCHIARI, Maria Tereza Duarte Paes. A (re)significação da paisagem no período contemporâneo. In: CORRÊA, Roberto Lobato e ROSENDAHL, Zeny (orgs.). Paisagem, imaginário e espaço. Rio de Janeiro: EDUERJ. p. 9-28. 2001. Disponivel em: <https://pt.scribd.com/doc/119538364/paisagemimaginario-espaco>. Acesso em: 27 jul. 2018.

RODRIGUEZ, J. M. M; SILVA, E. V. da; CAVALCANTI, A. P. B. Geoecologia das Paisagens: uma visão geossistêmica de análise ambiental. 4 ed. Fortaleza: Edições UFC, 2013.

SALVI, R. F. A questão pós-moderna e a Geografia. Geografia. Londrina, v. 9, n. 2, p. 95-111, jul./dez. 2000.

SANTOS, M. Metamorfose do Espaço Habitado. São Paulo: HUCITEC, 1997. cap 5.

TURNER, M. G; GARDNER, R. H; O'NEILL, R. V. Landscape Ecology in Theory and Pratic: Pattern and process. New York: Springer, 2001.

Recebido em: 23/12/2017

Aceito para publicação em: 17/09/2018 